\title{
Agroecologia e autenticidade: estilo de vida e gramáticas locais entre agricultores ecológicos do sul do Brasil
}

\author{
AGROECOLOGY AND AUTHENTICITY: LIFESTYLE AND LOCAL GRAMMAR AMONG \\ ECOLOGICAL FARMERS IN SOUTHERN BRAZIL
}

\section{AGROECOLOGÍA Y AUTENTICIDAD: ESTILO DE VIDA Y GRAMÁTICAS LOCALES ENTRE LOS AGRICULTORES ECOLÓGICOS DEL SUR DEL BRASIL}

\author{
Guilherme Radomsky*1 \\ guilherme.radomsky@ufrgs.br \\ Recibido: 5/2/2020 Aceptado: 28/8/2020
}

\begin{abstract}
Resumo
Neste artigo analiso a relação entre agroecologia, magia e autenticidade, resultado de pesquisa etnográfica realizada entre 2008 e 2009 na região oeste do estado de Santa Catarina, Brasil. Um problema no cotidiano de agricultores ecológicos é terem sucesso em atestar que produzem alimentos de modo sustentável, o que os faz colocar em movimento um conjunto de práticas, tais como a certificação ecológica endógena e um trabalho sistemático e público na agroecologia. Procuro mostrar que estes esforços não somente ressaltam os aspectos ambientais da produção em questão, mas tão ou mais relevante é que a agricultura ecológica envolve o estilo de viver cujo conjunto de características precisa aparecer nos alimentos. Relacionar este estilo de vida com os produtos ecológicos é uma trama complexa e examino esta conexão por meio das articulações entre magia, propriedades culturais e eficácia simbólica dando especial foco à gramática local dos processos em cena.
\end{abstract}

Palavras-chave: Ecologia, Agricultura familiar, Propriedade cultural

\begin{abstract}
In this article I analyze the relationship between agroecology, magic and authenticity. The discussion presents the results of an ethnographic research carried out between 2008 and 2009 in the western region of the state of Santa Catarina, Brazil. A problem in the everyday life of ecological farmers is how to succeed in certifying that they produce food in a sustainable manner, which makes them set in motion an ensemble of practices, such as endogenous ecological ecolabelling and systematic and public work in agroecology. I argue that these efforts not only highlight the environmental aspects of the production, but more relevant is that ecological farming implicates the lifestyle and a set of attributes that need to appear in food. Relating this lifestyle to ecological products is a complex challenge and I examine this connection through the articulations between magic, cultural properties and symbolic efficacy and analyze with greater attention the local grammar of the processes on stage.
\end{abstract}

Keywords: Ecology, Family farming, Cultural propiety

\section{Resumen}

En este artículo analizo la relación entre agroecología, magia y autenticidad, resultado de una investigación etnográfica realizada entre los años de 2008 y 2009 en la región oeste del estado de Santa Catarina, Brasil. Un problema en el cotidiano de

\footnotetext{
$1 *$ Universidade Federal do Rio Grande do Sul
}

Tekoporá ${ }^{\circledR}$. Centro Universitario de la Región Este. Universidad de la República (C) Radomsky (2020)

Este es un artículo de Acceso Abierto distribuido bajo licencia Creative Commons (CC BY NC 4.0) 
los agricultores ecológicos es sobre cómo tener éxito en comprobar que producen alimentos de modo sostenible. Esta situación los hace dinamizar un conjunto de prácticas, tales como la certificación ecológica endógena y un trabajo sistemático y público en la agroecología. Busco mostrar que estos esfuerzos no sólo resaltan los aspectos ambientales de la producción en cuestión, pero tan o más relevante es que la agricultura ecológica envuelve el estilo de vivir, cuyo conjunto de características necesita aparecer en los alimentos. Relacionar este estilo de vida con los productos ecológicos es una trama compleja. Examino esta conexión por medio de las articulaciones entre magia, propiedades culturales y eficacia simbólica, dando especial foco a la gramática local de los procesos en cena.

Palabras clave: Ecología, Agricultura familiar, Propiedad cultural

\section{Introdução}

Em pesquisa que realizei junto a agricultores ecologistas no Oeste do estado de Santa Catarina, sul do Brasil, em uma região não muito distante da fronteira com a Argentina, não pude deixar de ficar surpreso quando um dos meus interlocutores afirmou que estava feliz por ter retomado as vendas de suas hortaliças ecológicas para uma grande empresa, mas que sentia também uma leve e indesejada aflição. Relatou que no passado já havia mantido relações comerciais com eles. Perguntei o que estava acontecendo porque não pude compreender bem o duplo sentimento. Antonio me respondeu que a questão era saber se sua produção ecológica iria permanecer de fato ecológica no momento do consumo, ou seja, se na etapa final quando o alimento chegasse ao consumidor estaria separado dos convencionais que são produzidos com uso de veneno. Ele próprio já sabia: ao restabelecer sua relação com a empresa e expor sobre os modos de produzir em seu estabelecimento rural ouviu apenas a frase "é bom saber" da responsável na empresa, referindo-se que ao explicar sobre a agricultura ecológica na qual está engajado não obteve entusiasmo da sua interlocutora. Na prática, a fala demonstrava que a responsável poderia considerar relevante qualidade, mas que essa importância ao longo do processo de canalização para mercados poderia ser perdida.

Antonio era dos mais convictos da agricultura ecológica que conheci, um dos últimos do seu município a permanecer na agroecologia mesmo depois do grupo local ter tido vários problemas para se manter atuante. No entanto, a pergunta que colocava Antonio e que para ele envolvia dilemas era justamente: como saber que o alimento ecológico chegará ao consumidor de maneira clara? Como saber que sua produção seria identificada e demarcada com atributos de saúde e outras características do seu modo de produzir?

0 caso pode ser específico e até pouco representativo considerando o crescimento da produção e do consumo de produtos orgânicos no mundo, mas o problema em questão é de se destacar: grande preocupação de agricultores ecologistas é como tornar transparente que os alimentos produzidos por eles possam ser reconhecidos enquanto ambientalmente sustentáveis.

Há, evidentemente, situações distintas em jogo. Outro interlocutor que tive à época, professor universitário que fazia parte e era um dos protagonistas do grupo de consumidores ecologistas de Chapecó, maior cidade da região, mostrou outra face do processo. Na tentativa de organizar compras coletivas em uma rede de conhecidos usando a internet, algo ainda novo para a região naquele momento, alguns agricultores convencionais quase entraram na iniciativa por argumentarem terem mais produção ou afirmarem usar poucos produtos químicos nos cultivos, mas o grupo de consumidores foi firme e não aceitou. Indaguei naquele momento qual era a razão exata desta negativa e meu interlocutor enfatizou: "o produto da cesta tem que ser ecológico, porque se não for, contamina". A ideia de contaminação parece bastante expressiva do sentimento em relação, pois coloca uma questão de pureza e perigo, nos termos de Douglas 
(1991).

Não foi a única ocasião que alguém se referia de modo semelhante e a partir dos casos distintos - produtor e consumidor - assumi que esta relação colocava uma oposição entre "fora" e "dentro". 0 risco dos primeiros era que seus produtos se perdessem num "mar" de agricultura indiferenciada e com uso de agrotóxicos. 0 risco dos consumidores residia no aspecto interno, corporal, de ingestão, algo que não ocorria entre os agricultores, pois estes geralmente sabem o que estão comendo. Tais manifestações denotam uma oposição instigante e as tomo como inspiradoras para iniciar a reflexão aqui proposta. Em que pese esta discussão sobre pureza e perigo, de um lado, e fora vs. dentro, de outro, possa ser produtiva, opto a seguir por mobilizar outras perspectivas analíticas em favor de um debate mais orientado pela ação processual e contextual. $\mathrm{O}$ fato é que ambos os problemas nos fazem refletir sobre como são autenticados os alimentos sustentáveis; se na aparência uma fruta ou hortaliça ecológica pode ser virtualmente igual àquela que recebeu doses de agrotóxicos e outros agroquímicos, como atestar a sanidade nela presente?

A resposta que os procedimentos padrões têm dado a isto é recorrer a instrumentos normativos e de controle por agente externo, especialmente por meio de institutos certificadores acreditados por Estados ou entidades supra-estatais (tais como a União Europeia, por exemplo). 0 dilema aqui é que enquanto estas iniciativas são feitas por entes aferidores legítimos, vários atores têm reportado vicissitudes: por um lado, são usualmente órgãos de certificação orgânica, portanto de orientação mercadológica e para tal não importa que o mesmo produtor use pesticidas numa parte do estabelecimento rural e em outro setor da mesma invista em orgânicos. De outro lado, o próprio contrato entre agricultores e certificadoras estimula uma relação individual (sem envolver transição para sustentabilidade nos territórios) e os selos são comprados, ou seja, cada agricultor paga (e com valores caros) cada inspeção. Entretanto, mais complicado é que agricultores que já se envolveram neste tipo de relação relatam que a inspeção é feita uma vez ao ano e pouco se sabe o que os produtores realizam depois em suas terras. Aqui o ponto é que o sistema feito para ser mais eficiente possui eficácia por vezes questionada, conforme escutei de muitos atores em campo.

Como fazer, então, para que os produtos agrícolas ecológicos expressem mais do que meramente a conversão estratégica para venda em mercados? Como ser eficaz um sistema que seja amparado em monitoramento, sem controle externo (certificação paga) e que consiga também atestar que não se trata apenas de produção sem uso de pesticidas, mas de alimentos que relacionam todo o processo de trabalho e produção dos agricultores no seu cotidiano? A partir destas indagações, passei a perceber que havia uma gramática do processo de tornar visíveis as características dos produtos e mais ainda os atributos destacáveis das famílias produtoras.

A pesquisa de caráter etnográfico foi realizada junto a agricultores familiares ecologistas, consumidores e mediadores de organizações ou do Estado entre os anos de 2008 e 2009 na região oeste de Santa Catarina, no sul do Brasil. Todos eram membros da Rede Ecovida de Agroecologia, importante coletivo do sul do Brasil que congrega produtores em diferentes núcleos territoriais. A Rede já foi tema de análise de vários autores (Rover, 2011; Lucion, 2016, somente para citar dois) e não abordarei novamente em detalhes, com exceção de pontuar aspectos relevantes que importam a este artigo. Interessam mais neste momento a vida e o modo de trabalho dos agricultores (embora eu faça também alusão a outros atores durante a escrita) e menos a dimensão institucionalizada da Rede. Percorri para a investigação os municípios de Chapecó (mais populoso da região, com cerca de 200 mil habitantes), Novo Horizonte, Pinhalzinho, Guatambu, Quilombo e Seara para entrevistas, visitas a estabelecimentos rurais, observações em feiras, participação em eventos, reuniões da Rede 
Ecovida e outros episódios. À época, eram 123 agricultores certificados e em transição, dos quais acompanhei de fato em pesquisa um número muito menor. Ao longo do texto examino e apresento algumas das chaves interpretativas que me guiaram, os problemas advindos da gramática local em jogo sobre agricultura ecológica e as maneiras como os fenômenos se apresentaram em campo e me permitiram compreender os processos sociais da maneira como aqui exponho. Depois desta introdução, apresento a agricultura ecológica da região, logo após demonstro alguns eixos teóricos que foram fecundos para o entendimento dos problemas; faço também uma análise de práticas e como se fala por meio delas (e sobre elas) e ao final traço algumas conclusões.

\section{A agricultura ecológica no oeste do estado de Santa Catarina}

0 que faz os agroecologistas diferente dos demais é menos um jogo rígido de oposições e mais um conjunto de características que, se fossem observadas isoladamente, não forneceriam segurança suficiente para distinções. Isto porque a agricultura ecológica do oeste de Santa Catarina, tal como é também no norte do Rio Grande do Sul e no sudoeste do Paraná, é oriunda da tradicional agricultura familiar que ocupou os territórios no início do séc. XX tomando-os dos grupos indígenas ou ocupando o que as empresas de colonização lhes ofereciam. A ampla maioria migrou do estado do Rio Grande do Sul, onde as terras estavam mais escassas para os filhos de agricultores que desejavam se manter na atividade. Por essa razão, boa parte é de origem étnica germânica ou italiana e se reconhecem enquanto tal. A região oeste de Santa Catarina é marcada por um tecido social rural cuja agricultura é de estilo policultora, com matriz camponesa e que procura naturalizar as virtudes étnicas (Seyferth, 1990; Renk, 2000). Uma espécie de zona de contato na fase da colonização (Pratt, 1999) historicamente constituída propiciou a subalternização dos grupos indígenas da região.

Portanto, muitos dos agricultores ecológicos compartilham os mesmos atributos que os agricultores familiares (pois são familiares também): as propriedades rurais têm em média 17 hectares, a mão de obra é em geral familiar e com eventuais contratações de terceiros, a gestão é organizada pelo grupo doméstico; realizam escolhas pensando como os antepassados faziam (pelo menos como orientação de base), possuem aversão a riscos, medo de que crises drásticas possam levar as famílias a passarem fome e organizam associações ou cooperativas como forma de vínculo de trabalho e representação política.

Ainda assim, além destas, há características que são típicas das famílias agroecologistas, tais como a capacidade e a disposição para a experimentação com cultivos e criações. Isto ocorre em especial porque na agroecologia (diferente dos que plantam soja ou milho transgênico na região) não há receitas iguais para todos. Não há "pacote" tecnológico para aplicar de maneira padronizada. Os atores buscam otimizar a produção consorciada (diversas variedades agrícolas) nas pequenas áreas, tendo como finalidade a alta produtividade com menor impacto ambiental possível - retornarei a este tema logo adiante. Também se pode dizer que uma forma de pensamento sistêmico é fundamental e bastante recorrente, ainda que em certos casos isto não seja verbalizado. 0 modo sistêmico de trabalho é o que garante a agroecologia enquanto um complexo funcionamento em que as partes interagem: tanto o cultivo de massa verde para adubação, como o entendimento a respeito da participação de insetos e outros no crescimento de hortaliças, assim como a diversidade de cultivos juntos evita que as pragas ataquem unicamente uma variedade.

Esta percepção de que o conjunto de cultivos possui uma ecologia própria é central para que a produção ocorra, pois depende que a natureza faça um "trabalho" que lhe é próprio. Dessa 
maneira, é de se ressaltar esse distinto entendimento sobre o ambiente e sua dinâmica. 0 que se torna crucial é que ser agricultor ecológico de maneira nenhuma pode ser equacionado com uma mera opção estratégica econômica ou de ação utilitária, pois antes ocorre uma mudança de pensamento a respeito de como o mundo é e quais as consequências das nossas práticas cotidianas. Pude perceber que para muitos que escolheram esse caminho a agroecologia passou a fazer sentido, considerando que durante muito tempo se sentiram insatisfeitos com a produção convencional, ou relataram exploração de grandes agroindústrias ou ainda haviam sofrido algum tipo de contaminação durante o trabalho. Daí que certos interlocutores me falaram de que a mudança se deu por uma opção de vida ou por desejarem ter outro modo de viver.

Toda esta discussão não significa que mercados e expectativas quanto a ganhos econômicos sejam secundários, mas que há elementos para concluir que não se trata somente disto, caso contrário não precisariam modificar o estilo de viver e produziriam alimentos orgânicos quando fosse conveniente. Osmar, com quem partilhei alguns momentos em campo, é um exemplo dessa complexa relação, já que certa vez, contando sua história, me confidenciou que entrou na agroecologia por influência de uma familia que havia estudado o tema e também porque viveu uma crise: criava e vendia aves para uma grande empresa e sentia que a exploração era grande. Com pouca terra não conseguia mais dar conta. Afirmou que valeu a pena trocar, passou a ganhar mais dinheiro. Enquanto parecia me apresentar motivos bastante instrumentais, logo depois, estimulado pelas minhas perguntas, respondeu que também começou a se preocupar com a água e com o solo.

De certo modo, essa orientação de pensamento se choca parcialmente com a herança do saber-fazer no seio da família. Por um lado, os agricultores se colocam a questão de lembrar ou recordar coletivamente como os antepassados viviam e tomam isto como exemplar; de outro, a agricultura ecológica implica ruptura com o advento da modernização agropecuária que se tornou insidioso em diversas regiões do Brasil por meio de transformação da base tecnológica a partir dos anos 1960 (uso de aditivos e pesticidas, maquinário e sementes "melhoradas"). Eventualmente, o passado e sua rememoração criam crises ou conflitos surpreendentes, tais como relatados por pessoas que fizeram a transição para a agroecologia e ouviram de forma preconceituosa de seus vizinhos que "estavam voltando ao passado". Então, confundem-se recuperar práticas antigas e voltar de fato ao passado, como se fosse possível. Não deixa de ser curioso como isto é tema recorrente de reflexão da antropologia contemporânea, tal como o conhecido trabalho de Fabian (2013) sobre o Outro e o tempo e mesmo na observação de Bourdieu (2008) ao enfatizar que uma das formas de criar fronteiras entre grupos é utilizar o tempo como meio de medir distâncias sociais. Não resta dúvida que falar dos agricultores ecológicos de um modo geral sempre pode induzir que tais características em relação sugiram homogeneidade cultural, o que não é o caso. Embora neste trabalho eu enfatize as propriedades que são comuns, espero que ao longo do texto as menções às famílias destaque as particularidades de cada.

O trabalho coletivo é outro aspecto crucial para os ecológicos. Embora se estimule a formação de habilidades individuais para lidar com problemas que somente cada propriedade rural vivencia - e isto é perseguido por muitos como modo de inovar ou adaptar cultivos às suas áreas - a percepção de que na agroecologia ninguém está isolado é muito intensa. 0 contato constante entre as pessoas dos grupos ecológicos, não apenas por conta da certificação participativa, é propiciado e se torna rotina. A própria rotinização das interações (visita dos membros do grupo aos seus pares ou em relações semanais em feiras nas cidades) é parte da experiência coletiva e constitui um tipo de aprendizado muito peculiar: é difuso e vai se disseminando ao longo do tempo no território. 
Já os agricultores em sistema convencional neste quesito são muito diferentes. Tomando os casos bastante típicos na região dos que produzem soja, milho ou criam aves e suínos para vender a agroindústrias sua rotina é muito mais circunscrita sobre sua própria produção. As relações obrigatórias são de fato com as empresas e cooperativas ou com intermediários que compram os produtos. No caso dos que criam e vendem animais a forma de produção é regulada pelos compradores e os atores precisam seguir regras de caráter organizativo e sanitário. A isto os ecologistas contrapõe a satisfação de poderem ser inventivos e, por meio de relações solidárias (que facilmente se transformam em conflitos, cabe mencionar), buscarem com os demais como melhorar suas técnicas. Assim, diversificação de cultivos e criações, capacidade de experimentação em diálogo com os pares e certa autonomia no modo de trabalho são características também chaves que definem os ecológicos.

A agricultura familiar convencional mercantiliza etapas do processo produtivo (Ploeg, 1993), isto é, condiciona sua produção à intervenção de agentes ou tecnologias externas que são compradas. 0 agricultor ecológico, de sua parte, busca autonomia que possa gerar um ecossistema que se retroalimente. Produz-se leite e planta-se cana, que servem para o consumo e para a venda. Mas também com estes se faz o composto adubo orgânico. Com os restos de comida, de horta ou do pomar e de esterco, também se prepara a compostagem para adubação natural. 0 conjunto de cultivos plantados orienta-se para uma relação harmoniosa com outros organismos do solo (ervas, inços, insetos, minhocas e outros) e isso sugere uma leitura da paisagem que prima por uma interpretação relacional entre os seres vivos e inorgânicos. Portanto, o objetivo do sistema da agricultura ecológica, comentou um agricultor, é justamente não deixar o solo limpo com a terra aparecendo; quanto mais plantas nascem em meio às plantações, maior é o sinal de que o solo é fértil e está equilibrado. Mesmo com plantas que sejam competitivas com os cultivos principais é possível elaborar um manejo que as controle de modo sustentável.

Renato, agricultor de Chapecó com quem conversei algumas vezes e visitei sua terra, mostrou conhecer muito bem a dinâmica do ecossistema da plantação e argumentou a importância de deixar uma camada de mato para depois roçar e fazer uma "cama" (adubação verde). A noção de integração da propriedade se mostra evidente quando ele me apresentou seus açudes e como os peixes ali criados se alimentam do que já existe naturalmente na água, ou seja, ele não precisa fazer nada. Pode-se entender que a autonomia vem a ser identificada com a relação que se estabelece entre cultivos e criações. Isto significa que os agricultores representam sua propriedade rural como um sistema em que organismos geram outros organismos e que a sustentabilidade esteja vinculada à maior capacidade de resposta endógena dos agricultores aos problemas que enfrentam no cotidiano.

Todas estas questões são de difícil apreensão para quem não conhece o mundo da agricultura e da ecologia. Então, torna-se presente um dilema: como fazer para que esta realidade se faça conhecida pelos outros?

Os selos ecológicos podem ser ferramentas eficientes. São próprios da Rede Ecovida e todos os agricultores fazem uso deles em circunstâncias diversas. Em certos momentos, percebi que o selo funciona como uma maneira de tornar presente de modo simbólico quando o agricultor não está junto aos seus produtos; quando os mercados são feitos de redes mais amplas. Eventualmente, essa menção, que supõe uma virtual diminuição da distância, cria relações mais densas entre produtor e produto, segundo pude observar. Mas o que importa também é que neste caso o selo não é individual, ele não funciona tal como um rótulo que identificada cada um ou sua família. Identifica os produtores da rede. Em diversos relatos, agricultores falaram que se aproximar do consumidor, fazê-lo entender como é a produção 
ecológica e tudo o que ela envolve - já que envolve a integralidade do vivido dos produtores é mais relevante do que a simples etiqueta, tema que quero retornar adiante. De qualquer modo, trata-se constante argumentar e sustentar uma autenticidade garantida pela rede de agricultores que não é somente a respeito de processo de produção e sua relação com ambiente, mas do estilo de viver. Por essa razão que as características antes descritas são tão centrais no modo como se diferenciam dos demais.

Do que a literatura expõe e sendo breve nesta análise existem três campos particulares que pesquisadores observam a pertinência da noção de autenticidade: a pessoa (o self), as culturas e os objetos ou obras. A preocupação com a autenticidade se baseia na construção histórica dessa categoria sendo que no Ocidente o aparecimento se deu por volta do final da Idade Média europeia e que, dentre outras coisas, se organizou na busca de um eu individual autêntico (Handler, 1986). Handler também situa o fim do período medieval como momento em que a autenticidade se vinculou à sinceridade e ao indivíduo, num contexto em que se passou a acreditar que o mundo não era mais imediatamente acessível aos sentidos. Embora em estudo voltado a outro problema, Watt (1990) observou que o surgimento do romance moderno ligou-se à ideia de verdade cartesiana e que o realismo se tornou a marca deste gênero. Não menos importante, Watt também mostra que a expressão da verdade como verdade individual teve ápice entre a publicação das obras de Descartes e Locke. Do indivíduo para o coletivo, Handler $(1985,1986)$ argumenta que depois, no romantismo alemão, demarcou-se firmemente o desenvolvimento da busca por aquilo que é o autêntico da cultura (Lindholm, 2007).

Tem-se a impressão, assim, que o mundo ocidental vive uma progressiva sensação de perda de uma relação imediata e em si mesma autêntica entre as pessoas e destas com as coisas. No terceiro campo, Walter Benjamin publicou um dos textos mais influentes no século XX sobre a questão da autenticidade vinculada a objetos ou obras. A dimensão crítica de seu texto (Benjamin, 1985) é mostrar os dilemas entre o original e o problema da cópia no desenvolvimento tecnológico no capitalismo - a possível reprodutibilidade das obras - e o quanto isto levantou suspeitas sobre a originalidade e, consequentemente, sobre os seus valores.

0 problema a respeito de como autenticar processos e produtos parece rondar as preocupações dos agricultores ecológicos. Nas seções seguintes apresento detalhes e características de como isto se apresentou em campo e quais soluções são fornecidas pelos atores.

\section{0 estilo de viver e produzir que se transfere aos produtos}

Aproveito esta pausa na descrição dos eventos para seguir com algumas noções teóricas que se mostraram pertinentes a este trabalho. Estilo de vida se define como um sistema de práticas que determinam uma classe ou grupo e, apesar de existirem muitas noções aproximadas na literatura (modos de vida, estilos de agricultura), Pierre Bourdieu ofereceu uma conceituação adequada o suficiente para o que busco argumentar. 0 estilo se refere a um conjunto de propriedades distintivas e de atitudes (Bourdieu, 2007) e pode ser dado tanto por hábitos e preferências, como por capitais herdados ou por propriedades de grupos. É de se destacar que Bourdieu (2007) se refere ao estilo de viver sob a ótica do pertencimento e do sistema de signos que são associados a grupos ou à classe, o que converge para o que percebi ao longo do trabalho de campo a respeito de propriedades culturais dos agricultores ecológicos.

Antes ainda de voltar às dimensões efetivamente etnográficas, circunscrevo alguns caminhos analíticos adicionais com os quais tentei compreender os problemas até agora 
mencionados e proponho uma chave interpretativa que se ampara no trabalho de Bourdieu e Delsaut (2008) sobre os costureiros franceses e o poder da assinatura na moda de alguém consagrado para autenticação e eficácia no campo. Esta análise tem expressiva relação com o trabalho original de Mauss e Hubert (2003) sobre a magia e de Lévi-Strauss (1967a, 1967b) acerca do feiticeiro, sua magia e a eficácia simbólica.

O que se pode afirmar, do ponto de vista da pesquisa de campo, é que os produtos são "transformados" quando recebem o selo de certificação ecológica, mas não se trata somente de um fenômeno de acreditação formal, ainda que esse é definitivamente relevante. Todo um conjunto de relações se processa para esta consecução. A ressignificação dos objetos, a depender do esforço que fazem os próprios agricultores, é fundamental, e o caráter simbólico disto é que impera. A eficácia se dará se os atores puderem fazer aparecer identidades e estilo de viver diretamente em seus produtos, algo que não é automático. Daí decorre a importância das dimensões processuais da ação, pois pude entender em campo que depende das capacidades dos agricultores para, por meio de grande esforço, conseguirem mostrar ao restante da sociedade que os alimentos que produzem têm algo de suas próprias identidades sociais.

A transmissão de propriedades é uma das formas clássicas nas quais se apresenta a magia. Para Mauss e Hubert (2003), a questão é que ela coloca um problema básico de transformação sem mudança da base física dos objetos ou, pelo menos, isto aparecerá com um demarcador operado pelo ato mágico. Este foi tema de reflexão por antropólogos contemporâneos ou anteriores a Mauss (e as investigações seguem atualmente, embora outros pontos de partida teóricos apareçam): como entender que objetos são modificados por meio de palavras ou com o simples toque de alguém? São as forças da própria sociedade, e isto importa, que organizam a eficácia da magia, justamente porque as pessoas vivem em um mundo em que ela é parte constitutiva e nela acreditam. Contudo, nem todas as pessoas podem efetivar um ato mágico, ficando a cargo de agentes específicos (curandeiros, mágicos, etc.).

Quando em análise muito distinta e focada em outros aspectos Marilyn Strathern observou que nos regimes de propriedade cultural (que podem ou não serem protegidos por sistemas de proteção mais formais e legais) faz sentido entender que esta pode ser verificada na sua capacidade de transmissão (entre gerações, por exemplo), a autora (Strathern, 1996) sublinhou que o elemento fundamental desta transmissão para os processos de patrimonialização ou de direitos intelectuais é que ela possa ser autenticada. Isto é, povos e conhecimentos tradicionais se diferenciam dos inventores ocidentais porque - entre outras características - os portadores de inovações são difusos. Em suma, é o coletivo o portador do poder de criar, instituir e manter tradições. Os sistemas coletivos de propriedade cultural são diferentes dos direitos intelectuais típicos do Ocidente (patente, copyright, marca registrada, etc.), uma vez que há a tendência de preservar a transmissibilidade coletiva ao longo do tempo - e autenticar isto internamente - sem privatizar e restringir (também tema em Strathern e Hirsch, 2004). Entretanto, sabe-se quem faz parte dos grupos culturais e portanto têm respaldo para alegar pertencimento social a eles.

Considerando os agricultores ecológicos com os quais realizei pesquisa, estas dimensões se apresentam na forma de condições sobre quem é, quem não é, quem pode ser agricultor ecológico na região, pois está claro que muitos podem produzir de modo ecológico, mas nem todos partilham das características que definem agricultores ecológicos familiares. Estamos no âmbito de propriedades que são culturais, historicamente passíveis de serem legitimamente reconhecidas, e cuja capacidade de fazer valer a produção dos alimentos enquanto portadores de características especiais depende de eficácia simbólica em uma sociedade que fornece 
significativo valor ao que é autêntico. 0 pertencimento, então, é central.

Antes de avançar nesta direção, gostaria de recuperar ainda, na ligação mais direta com Mauss e Hubert, os escritos de Bourdieu (2008) e Bourdieu e Delsaut (2008). Bourdieu afirma que "a eficácia quase mágica da assinatura não é outra coisa senão o poder, reconhecido a alguns, de mobilizar a energia simbólica produzida pelo funcionamento de todo o campo [...]" (Bourdieu 2008, p. 28). Vale a pena ressaltar isto: trata-se de entender que a magia funciona em sociedade porque é o coletivo que instauram tanto sua possibilidade como sua potencialidade de transformação da realidade.

Por seu turno, Bourdieu e Delsaut (2008) mostraram que na alquimia social os produtos se modificam sem que suas propriedades materiais tenham qualquer modificação. Tal como na transformação da hóstia em corpo de cristo na eucaristia da religião católica conforme seus teólogos, na assinatura do costureiro de grife a peça adquire um diferencial que pode ser entendida como um ato de magia, que os autores denominaram transubstanciação simbólica (Bourdieu, Delsaut, 2008). O bem material pode ser qualquer, mas a assinatura do consagrado faz o processo de modificação imaterial. 0 mesmo vale para a assinatura de uma escultura ou pintura por um renomado artista quando consagrado. Portanto, para que eu possa retomar o caso em análise, não se trata de afirmar que os produtos ecológicos não sejam diferentes dos convencionais que portam agroquímicos e sim de observar que não é uma tarefa fácil para os agricultores esta publicização se não houver um conjunto de operações que certifiquem a mudança. Ademais, alimentos ecológicos e orgânicos podem ser idênticos, mas o que então tornará o ecológico especial? No limite, sem a certificação ou sem que os próprios ecologistas gerem a eficácia o produto segue indiferenciado aos olhos dos outros.

Mauss e Hubert esclarecem que os ritos mágicos são comumente formais, o que nos dá uma pista. Na certificação, espera-se que o ato seja pormenorizado, orquestrado com base em procedimentos passíveis de repetição, ritualizado com agentes no campo e que, ademais, que ela seja o ato culminante em que a conversão da propriedade rural teve uma duração de tempo geralmente não menor do que um ano - ou seja, um conjunto de expectativas é acumulado. Ocorrem reuniões informativas, procedimentos educativos, controle por parte de técnicos ou outras pessoas envolvidas, artifícios burocráticos, divulgação das normas para os agricultores em transição, preenchimento de formulários, desenho da propriedade pela família em transição, acompanhamento de eventos, monitoramento e verificação das áreas de cultivo.

Ainda que se esperem tais passos, o fato é que na prática a Rede Ecovida organiza sua concessão de selos de maneira a enfatizar o processo de acompanhamento, integralidade da agroecologia na propriedade rural, monitoramento participativo feito pelos próprios agricultores e transparência dos atos. Há um processo de trabalho das famílias ao longo do tempo e isto inclui incorporar e performatizar o conjunto de características antes descritas. Vale ainda dizer que nem tudo na agricultura ecológica se resume ao processo de certificação. Este pode ser o resultado de um trabalho anterior e isto será retomado adiante; aqui quero ressaltar que do que pude compartilhar com os atores em campo há um conjunto de situações que podem ser tão relevantes quanto à atribuição dos selos.

Em fins de 2008, numa reunião regular do grupo de Chapecó fez-se uma avaliação do andamento dos trabalhos ao longo do ano. Nela, reforçou-se o caráter das relações diretas com o consumidor, "primordial é ter o consumidor de perto, criar vínculo com ele", afirmou um dos líderes do grupo. À medida que afirmaram que o selo deveria ser secundário afirmavam que com as distâncias dos mercados atuais era comum que os selos fossem - tal como antes havia adiantado - "atestado de presença" dos ecológicos em outros lugares. Essa distância o selo procurava diminuir simbolicamente. 0 curioso é que nas vendas diretas face a face, a dispensa das certificações é amparada legalmente e também os atores as consideram menos 
importantes, o que vem a nos indicar o quanto os selos podem ser identificadores de propriedades imateriais que os alimentos carregam além de identificar o grupo quando os produtos viajam distâncias.

Em outro ponto de vista, o que se tornava enigmático por vezes era a dificuldade de alguém dizer com certeza e que ressoasse em opiniões dos demais o que faz o alimento ecológico distinto. Um dos produtores me disse numa ocasião: "os consumidores procuram os produtos ecológicos por causa da saúde, da segurança de não ter veneno". Outro, do município de Novo Horizonte, ao norte de Chapecó, comentou: "a ideia da agroecologia é fazer de outro modo, fazer com carinho o trabalho...”. Às vezes, fica implícito o que o produto possui, ou seja, não é necessário sequer falar: "quando a gente vende para o supermercado, a gente procura colocar um bom preço, não tão alto, mas um preço bom [ou seja, maior que o convencional]". Mas por que razão, afinal? Está claro, ele não necessita me explicar que há um "algo mais" nos seus produtos. Outra face da moeda também apareceu: seguidamente escutei em campo que os alimentos convencionais é que deveriam utilizar selos negativos. Então, o ponto a ser destacado é que estes têm algo que os ecológicos não têm: "a certificação deveria ser para os transgênicos e os que usam veneno", comentou José Roberto, mediador da Rede. Ao adquirir um alimento com uso de venenos e adubos artificiais o consumidor compra algo que vem junto com o produto, isto é, aquilo que ele não quer. Assim, o ecológico ora possui algo mais - agrega em saúde, bem-estar, valores ecológicos -, ora possui algo menos.

Não pude deixar de observar que todos os atributos que ora coincidem, ora parecem se afastar e, principalmente, remetem em muitos casos a frases sem fechamento e definição exata ("alimento produzido de outro modo", "produção alternativa", "possuem algo mais", "possuem algo menos") ecoavam o conhecido significante flutuante examinado por LéviStrauss, que supõe um valor simbólico que se opõe à ausência de significação embora não tenha significado particular (Lévi-Strauss, 2003). No "algo mais" dos produtos agroecológicos, cujas características são sim enumeradas e reconhecidas pelas pessoas sempre de modo incompleto e irregular, reside sua força.

Recupero também a proposta analítica de Bourdieu porque ela é pertinente para o modo como abarca a condição ativa dos agentes disputando espaços de reconhecimento e bem recupera os trabalhos anteriores de Lévi-Strauss sobre a eficácia simbólica e o feitiço (LéviStrauss, 1967a, 1967b). Este panorama analítico (Mauss, Lévi-Strauss e Bourdieu) promove pontos de vista sobre o problema em questão, assim como - e é inevitável - deixa de fora potencialidades teóricas distintas. Tal opção favorece a interpretação por meio do que ao longo do séc. XX se observou como sendo o poder constitutivo da linguagem, das palavras e da classificação simbólica, que são cruciais para o caso tema da minha reflexão . Conforme consegui observar, a eficácia está em sustentar - seja por meio das certificações, seja por trabalho coletivo e sistemático com a agroecologia e publicização de seus benefícios - que os alimentos ecológicos portam aquele "algo mais" e também "algo menos", pois não são administrados venenos nem demais aditivos. Portanto, o que se passa é um processo de transferência e de subtração simbólica, visto que o produto parece ter algo que os demais não contêm e simultaneamente não carrega aditivos nocivos à saúde humana, ao solo e à água. Além disso, os agroecologistas se apresentam sempre como diferentes dos produtores rurais de orgânicos. 


\section{As relações e as gramáticas compartilhadas}

Conforme descrevi anteriormente, tanto agricultores como consumidores mostram encontros e desencontros quando se referem à qualidade especial dos alimentos ecológicos. Usando muitas vezes a palavra "outro" com sentido de algo alternativo ao convencional ("produção de outro modo"; um "outro sabor", e outras variações já descritas) remetiam geralmente aos aspectos de "algo mais/ algo menos" que se opõem à ausência de significação. Volto a me referir a isto para destacar que não se trata de não saber, mas que existem coincidências nos relatos e também algumas incertezas do que torna especial o alimento ecológico; o que geralmente ocorre é que existe a menção à distinção dos produtos. Mas, observando-se a relação entre práticas e produtos, ou seja, a vida em si dos agricultores familiares ecológicos, parecia-me cada vez mais transparente que a dimensão central em jogo ultrapassava os produtos somente e incluía outra dimensão.

Com Antonio, já apresentado no texto anteriormente, conversando sobre o que a certificação proporciona à agricultura familiar, afirmou com certeza e de um modo muito simples: "a certificação é prova de que existe todo um trabalho por trás do selo". Isto nos dá pistas significativas para entender. Em outra situação, estive visitando Laudemar agricultor do município de Seara, próximo à Chapecó, e ele relatou que "tem consumidor que vê, na feira onde exponho meus produtos, a uva [em outro estande] vinda de fora que tem a aparência mais bonita que a minha, mas mesmo assim ele compra a minha, pelo sabor, pela qualidade... ele já a conhece." O fato de conhecer é que aqui chama a atenção. E muito seguidamente houve comentários a respeito de como os consumidores em geral em nossa sociedade têm pouca noção do que se passa nas propriedades rurais, mais ainda entre os ecológicos. Osmar, um dos agricultores que manifestou isto admite que seria interessante que o consumidor fosse à propriedade conhecer seu modo de trabalho, uma vez que isto teria um efeito sobre a pessoa. Nas reuniões do grupo de Chapecó também escutei as mesmas falas, tal como a ideia de fazer atividades que possam "ganhar o consumidor", cuja tônica tem evidentemente uma estratégia mercadológica, porém conduz a reflexão à mesma pauta, ter segurança que a sociedade entende o que está ocorrendo nas áreas rurais e que não é fácil produzir sem uso de pesticidas.

Quando Antonio me contou certa vez que uma frequente compradora de suas hortaliças lhe falou "tuas verduras são tuas verduras" tive a forte impressão que o terreno da gramática oportunizava, como considerou Strathern (1999), que certos processos que vivemos nos colocam no "limite de uma certa linguagem". Neste caso, a antropóloga referia-se a como as categorias de propriedade intelectual empurravam ao limite nossa capacidade (cultural) de dar conta desta realidade. Aqui também o que explica a frase da consumidora é a ênfase da fala no segundo "tuas", pois o que se compreende é que ela sugeria que aquilo que o produtor fazia era somente ele quem conseguia fazer, estes alimentos eram especiais.

Assim, estamos também no limite do que os selos podem proporcionar, pois se alimentos ecológicos e orgânicos são virtualmente iguais quanto aos requisitos ambientais mínimos, e os selos ecológicos da Ecovida são iguais para toda a Rede, há sempre situações da relação agricultor/consumir que particularizam esta interação e fazem com que certas pessoas sejam especiais no que fazem (tanto o caso das hortaliças como o das uvas, de Laudemar acima, sugerem isto). Se o selo é um dispositivo fundamental que gera confiança e autenticidade ele não extingue as identificações particulares de cada produtor (ou cada família, na maioria das vezes) e as formas como são reconhecidos. Ainda assim, se ao olho do consumidor é possível dizer que os produtos convencionais e ecológicos são difíceis de distinguir é possível ver que nos casos de maior particularização e identificação (produto e família produtora) processos ou performances se mesclam com o resultado final que é o produto, isto é, o alimento ecológico 
valorizado por sua peculiaridade.

Este esforço por fazer que se destaquem as características do estilo de viver e os processos de trabalho dos agricultores não é posto em marcha somente por eles mesmos. Os técnicos mediadores (ou simplesmente mediadores por adesão ideológica) são bastante envolvidos em procurar demonstrar as relações entre propriedades que são particulares aos agricultores e produtos. Um dos interlocutores com quem conversei seguidamente e que os demais consideravam um mediador ativo do grupo me relatou que havia uma dificuldade no trabalho rural neste caso porque o uso da mão de obra é muito expressiva (maquinários são poucos). Os que fazem a transição para a agroecologia sentem esta penosidade: o tempo de trabalho aumenta, em que pese aumentem também a sensação de bem-estar e a autonomia. $\mathrm{E}$ não era só este ponto que ele destacava. As lutas políticas que instituíram a agricultura ecológica não eram reconhecidas, lutas essas que forçaram o Estado a fazer políticas públicas para a área bem como conceder espaços de comercialização. Ressaltou, assim, "a importância dos selos - e também eventos e lutas políticas - para as pessoas poderem ver que tem uma agricultura familiar por trás".

Outro mediador também muito ativo fez referências semelhantes. Além de insistir no argumento da intensificação do trabalho na roça fez menção aos riscos de perdas de safras quando se faz manejo ecológico . Qualquer praga não controlada por recursos biológicos pode ser devastadora. Nesse sentido, foi claro em dizer que há, por trás, o aumento de custos de produção e esse pode permanecer oculto para a grande maioria das pessoas. 0 agroecologista deve justificar que seu trabalho envolve estes dois problemas relativos ao processo de produção: o uso de força de trabalho (familiar) para atividades usualmente manuais e o risco de perdas de safras. Ambos os casos são processos sociais que devem aparecer nos produtos. Será de fundamental relevância que os agricultores consigam obter sucesso em operar a alquimia. Ela será uma peça na complexa trama que permite aparecerem as características especiais do seu trabalho, dos seus produtos e do seu estilo de vida à sociedade.

0 estudo de Renting, Marsden e Banks (2003) mostrou que existe uma parcela de consumidores urbanos hoje ávidos por restabelecer ligações mais profundas com o mundo agrário e as iniciativas podem encurtar distâncias reais ou estabelecer relações simbólicas, o que os selos ecológicos - por atestarem atributos de sustentabilidade por onde circulam podem performatizar. A certificação pode ter o potencial de uma informação precisa e garantida: quando os alimentos viajam distâncias e os consumidores não têm acesso direto às famílias agricultoras ecológicas eles são eficazes na identificação do grupo ou das redes (também em Winter, 2003).

A gramática que oscila entre "o que está por trás" e "fazer as pessoas verem" deu a este pesquisador a sensação que de algum modo as categorias de essência e aparência da cultura ocidental se apresentam de maneira específica, pois revelar é situar o horizonte dos processos não bem conhecidos do trabalho e da vida dos agricultores ecológicos.

\section{Considerações finais}

A capacidade dos agricultores serem reconhecidos individualmente como produtores de alimentos ecológicos muitas vezes ocorre com a identificação empática entre comprador e agricultor, tal como os exemplos aqui demonstrados. Porém, isto pode fazer parecer que a agroecologia é ato de um sujeito de liberdade que numa ação voluntária rearticula toda a gama de percepções e relações dos outros para consigo. Para além desta relação entre pessoas é o coletivo ou, neste caso analisado, a rede que se sustenta como operadora e 
garantidora de prestígio. Sem o trabalho anterior e coletivo da rede a agroecologia teria capacidade muito menor de adesão social, mesmo existindo sujeitos que individualmente possam protagonizar.

Como uma espécie de dádiva da rede o lento processo de disseminação da agroecologia funciona por meio do coletivo. Por isso a luta contra as empresas ou grandes cooperativas que individualizam o trabalho, destituindo laços comunitários e tornando a relação meramente entre família rural e corporação.

Um trabalho que não se percebe e tampouco se compreende claramente em sociedade: apesar do crescimento pelo interesse em consumo de alimentos ecológicos ou orgânicos nas últimas décadas, os agricultores ecologistas com quem tive a satisfação de compartilhar o tempo me expuseram a dificuldade de conseguir mostrar que produção sustentável no campo não é fácil. É necessário que a sociedade entenda que há um trabalho sendo realizado. Este esforço pode permanecer invisível e as performances, os selos de certificação gerados de maneira endógena e as gramáticas usadas em locais públicos procuram recuperar e mostrar que não somente preservação dos solos, plantas e água ocorre, mas todo o estilo de viver no campo é alçado ao centro do problema. Assim também estão articuladas as relações entre alimentos e processos, propriedades físicas e propriedades culturais imateriais, e igualmente o potencial de operar adequadamente determinada alquimia para distinguir aquilo que pode permanecer indiferenciado aos olhos de outros.

Fazer valer "algo mais" e também "algo menos", como exponho, é tarefa que necessita do trabalho dos agricultores em associação a outros atores. Por isto a consideração com a agroecologia é um processo que possui uma história e precisa de muito empenho. A gramática que apresentei em que os agricultores dizem constantemente existir um trabalho oculto que precisa ser visto pela sociedade importa muito. Esta proposição dá a dimensão do que querem para uma agricultura sustentável: que nela seja possível se valorizarem as habilidades coletivas e individuais dos produtores e que o trabalho no campo seja compreendido por quem nele não vive.

A agricultura orgânica nos mercados globais viveu uma intensa proliferação de institutos e empresas certificadoras porque percebeu que a potência dos selos reside em transformar a atenção dos consumidores e intermediários sobre estes alimentos e atestar sua qualidade. Quando a dúvida do que é autêntico se torna mais expressiva ela não questiona se ainda existiria valor diferente entre o original e a cópia. Parece gerar ainda mais força à ideia do genuíno, pois haverá esforços para diferenciar e destacar o que é mais ou menos autêntico. A autenticidade se transforma em valor para uma sociedade que atribui poderes à unicidade, à originalidade, ao verdadeiro. Nos termos locais, ela se vincula ao que é mais natural, ao que é da agricultura familiar ecológica, ao que pode remeter de fato a processos sustentáveis e ao que constitui manutenção de um estilo de viver no campo.

\section{Referencias}

Benjamim, W. (1985). A obra de arte na era de sua reprodutibilidade técnica. En W Benjamim, Obras escolhidas - magia, técnica, arte e política: ensaios de literatura e história da cultura. (pp. 165-196). São Paulo: Brasiliense. V. 1.

Bourdieu, P. (2007). A distinção: crítica social do julgamento. São Paulo: Edusp; Porto Alegre: 
Zouk.

Bourdieu, P. (2008). A produção da crença: contribuição para uma economia dos bens simbólicos. En P. Bourdieu, A produção da crença: contribuição para uma economia dos bens simbólicos. (pp. 17-111). São Paulo: Zouk.

Bourdieu, P. y Delsaut, I. (2008). 0 costureiro e sua grife: contribuição para uma teoria da magia. En P. Bourdieu, A produção da crença: contribuição para uma economia dos bens simbólicos. (pp. 113-190). São Paulo: Zouk.

Douglas, M. (1991). Pureza e perigo. Lisboa: Edições 70.

Fabian, J. (2013). O tempo e o outro: como a antropologia estabelece seu objeto. Petrópolis: Vozes.

Handler, R. (1985). On having a culture: nationalism and the preservation of Quebec's patrimoine. En G. stocking (Ed.), Objects and others: essays on museums and material culture. (pp. 192-217). Madison: University of Wisconsin Press.

Handler, R. (1986). Authenticity. Anthropology Today, 2(1), pp. 2-4.

Janis, M. (2014). Patenting plants: a comparative synthesis. En R. Okediji y M. Bagley (Ed.), Patent law in global perspective. (pp. 213-242). Oxford: Oxford University Press.

Lévi-Strauss, C. (1967a). A eficácia simbólica. En C. Lévi-Strauss, Antropologia estrutural I. (pp. 215-236). Rio de Janeiro: Tempo Brasileiro.

Lévi-Strauss, C. (1967b). 0 feiticeiro e sua magia. En C. Lévi-Strauss, Antropologia estrutural I. (pp. 193-213). Rio de Janeiro: Tempo Brasileiro.

Lévi-Strauss, C. (2003). Introdução à obra de Marcel Mauss. En M. Mauss, Sociologia e Antropologia. (pp. 11-46) São Paulo: Cosac \& Naify.

Lindholm, C. (2007). Culture and identity: the history, theory, and practice of psychological anthropology. London: Oneworld Publications.

Lucion, J. (2016). A gramática por trás do selo: agroecologia e processos de certificação participativos. (Mestrado em Ciências Sociais), Universidade Federal de Santa Maria, Santa Maria.

Mauss, M. y Hubert, H. (2003). Esboço de uma teoria geral da magia. En M. Mauss. Sociologia e 
Antropologia. (pp. 47-181). São Paulo: Cosac \& Naify.

Mauss, M. (2003). Ensaio sobre a dádiva: forma e razão da troca nas sociedades arcaicas. En M. Mauss. Sociologia e Antropologia. (pp. 183-314). São Paulo: Cosac \& Naify.

Palombi, L. (2009). Gene cartels: biotech patents in the age of free trade. Elgar: Chetelham.

Ploeg, J. D. van der. (1993). El Processo de trabajo agricola y la mercantilizacion. En E. Sevilla Guzman y M. González de Molina (Ed.). Ecologia, campesinado y historia. (pp. 153-195). Madrid: La Piqueta.

Pratt, M. L. (1999). Os olhos do império. Retratos de viagem e transculturação. São Paulo: EDUSC.

Renk, A. (2000). Sociodicéia às avessas. Chapecó: Grifos.

Renting, H., Marsden, T. y Banks, J. (2003). Understanding alternative food networks: exploring the role of short food supply chains in rural development. Environment and Planning, 35, pp. 393-411.

Rover, 0. (2011). Agroecologia, mercado e inovação social: o caso da Rede Ecovida de Agroecologia. Ciências Sociais Unisinos, (47) pp. 56-63.

Seyferth, G. (1990). Imigração e cultura no Brasil. Brasília: Ed. da UnB.

Strathern, M. (1996). Potential property. Intellectual rights and property in persons. Social Anthropology, 4 (1), pp. 17-32.

Strathern, M. (1999). No limite de uma certa linguagem (entrevista a E. Viveiros de Castro e Carlos Fausto). Mana: estudos de antropologia social, 5 (2). pp. 157-175.

Strathern, M. y Hirsch, E. (Ed.). (2004). Transactions and creations: property debates and the stimulus of Melanesia. New York: Berghahn Books.

Watt, I. (1990). A ascensão do Romance: estudos sobre Defoe, Richardson e Fielding. São Paulo: Companhia das Letras.

Winter, M. (2003). Geographies of food: agro-food geographies making reconnections. Progress in Human Geography, 27 (4), pp. 505-513. 